\section{Learning Experiences and Practices of Elementary Teacher Candidates on the Use of Emerging Technology: A Grounded Theory Approach}

\author{
Received: 14 August 2017 \\ Revised: 06 Sept. 2017 \\ Accepted: 18 Sept. 2017 \\ ISSN: 1307-9298 \\ Copyright (C IEJEE \\ www.iejee.com
}

DOI: 10.26822/iejee.2017236118

\begin{abstract}
The purpose of this study is to understand the phenomenon of the "professional journey" of elementary teacher candidates (ETC) both as learners and as teachers by exploring their learning experiences and practices regarding the virtual reality (VR) platform called Second Life (SL). Using the grounded theory approach, we designed an insider-led work-based study, synthesizing an outsider perspective. We collected data from 229 ETCs enrolled in science methods course over three academic years including semi-open ended reflective questionnaire, science journal notebooks, 5E science lesson plans, peer teaching classroom observations, and instructor's semester notebooks. Results indicate that as a VR platform, SL provided unique learning experiences that encourage discovering, problem solving, or accidental learning for these mostly first-time user ETCs. Three themes emerged in terms of perceptions of integrating VR into science teaching: (1) skeptical integrators (29\%), (2) observant integrators (59\%), and (3) innovative integrators (12\%). However, none of the ETC collaborative groups integrated a VR platform during their 5E science lesson planning activities, demonstrating the gap between learning experiences and practices. Finally, we converged analysis results with related literature to develop a theory. This study contributes to the discussions on preparing teachers for the 21 st century in which all will live in a technology-accelerated society.
\end{abstract}

Keywords: Elementary teacher candidates, technology integration, emerging technology, virtual reality, second life.

\section{Introduction}

Digital citizenship is no longer optional, but necessary, as we are living in a fast-evolving era of the Information and Communication Technology (ICT) world. This revolutionary movement from an analogue-based to a digital-based society has also changed the types of occupations needed; the roles of creative individuals as the key agents of change; the ways people collaborate with others and interact with digital devices; and, the ways ideas are developed, shared, and distributed (deSessa, 2000; Friedman, 2005). For some scholars, our digital-based society is recognized as an exciting time and as a powerful catalyst for rethinking innovative ways to teach and learn science (deSessa, 2000; Slotta \& Linn, 2009).

For many decades, the needs and demands for preparing the workforce in the fields of science, technology, engineering and mathematics (STEM) have increased; at least this is the case in the United States (Kuenzi, 2008; National Commission on Excellence in Education [NCEE], 1983; National Academy of Science [NAS], 2010). The national efforts to improve student achievement in science and mathematics have also intensified in the U.S. (National Science Board [NSB], 2006). For many years, teacher shortage and inadequate preparation of highly qualified teachers in these areas have remained a challenge for the nation (The California Council on Science and Technology [CCST], 2007; Triangle Coalition for STEM education, 2017).
Still, there is a limited collective understanding on how to increase the quality of STEM education, how to prepare highly qualified science and math teachers, and how to enlarge the STEM workforce.

The role of teachers is considered a critical component in STEM fields (CCST, 2007). Some believe that high-quality teachers would induce meaningful learning and, subsequently, increase the number of students who choose STEM career paths (NSB, 2006). This, in turn, would partially solve the challenge of high demand for STEMskilled workers in the U.S. (NSB, 2006; U.S. Congress Joint Economic Committee, 2012). In spite of this well documented need, the CCST report acknowledged the fact that there is a lack of well-prepared and effective teachers who teach science and mathematics at the secondary level. Furthermore, less than one percent of the available federal STEM resources for teacher performance improvements have been dedicated to preparing future teachers-only $\$ 0.43$ million out of $\$ 312$ million available (National Science and Technology Council [NSTC], 2011). Among these investments, there were only five programs that focused on STEM fields for K-8 pre-service elementary teachers (NSTC, 2011).

Some teacher education programs (TEP), however, shed light on preparing prospective teachers. For instance, Klenier, Thomas, Lewis, and Greene's (2007) report indicates that more than 90 percent of the identified TEP

\footnotetext{
${ }^{a, *}$ Corresponding author: Eunjin Bahng, School of Education, College of Human Sciences, lowa State University, $1740 \mathrm{D}$ Lagomarcino Hall, 901 Stange Road, Ames, lowa 50011-1041, USA. E-mail: ejbang@iastate.edu
}

${ }^{b}$ Department of History Education, Hongik University, 94 Wausan-ro, Mapo-gu, 04066, Seoul, South Korea. E-mail: mimilee@hongik.ac.kr 
were already integrating technology into instruction, which ranged from utilizing Internet resources to content specific software tools. 93 percent of the participating institutions reported that they teach educational technology within methods courses. When investigating factors that were considered as barriers to integrating educational technology into programs, pre-service teachers' lack of interest and limited skills and knowledge were not considered as significant barriers during program coursework or field experiences. When it comes to integrating technology into field experiences, competing priorities in the classroom and available technology infrastructure in the schools were the two most frequent barriers to the participating institutions (Klenier et al., 2007).

\section{The Purpose of Study}

The elementary teacher candidates (ETCS) in this study were in a teacher preparation program where digital citizenship and technology integration with instruction were highly valued. Towards the end of the 4-year program, the ETCs take a science methods course that was designed for them to engage in a new kind of learning and instruction using emerging technologies, specifically a Virtual Reality (VR) platform within which the ETCs are avatars. This study explored the journey of these ETCS, specifically their learning experiences and practices regarding a VR platform called Second Life (SL), which is a 3D digital world. Adopting the grounded theory approach as a research method, this study was structured as an insider-led work based study while synthesizing an outsider perspective. The questions central to this study were:

1. What was the nature of the learning experiences when elementary teacher candidates were engaged in VR activity?

2. How did elementary teacher candidates perceive integrating VR platforms into their science teaching?

3. What did the teaching practices of elementary teacher candidates look like when they integrated VR platforms within the $5 \mathrm{E}$ instructional model?

\section{Working Definition of Elementary Teacher Candidates} (ETCS).

ETCS exhibit many characteristics and these are well identified in the literature (e.g., Bleicher, 2006; Crowther \& Bonnstetter, 1997; Newman, Abell, Hubbard, McDonald, Otaala, \& Martini, 2004). ETCs enter the science methods course with formal preparation from only two or three courses in the life sciences and physical sciences during secondary school or university studies; therefore, it is likely they lack sufficient subject matter background. They may have negative and/or indifferent attitudes towards science and science teaching and, as a result, may lack confidence in science teaching. The students often are not well-versed in inquiry-based science teaching processes that promote the use of evidence, logic, creativity, reasoning, thinking, and communication skills, possibly because they are heavily focused on their grades and many would prefer to be taught in a didactic way (i.e., simply memorizing facts and taking tests) that is more comfortable to them. During the course, many may feel they have learned nothing from inquiry-based learning and will struggle to identify concepts they have learned through inquiry-based learning. Finally, most believe that there are always correct answers in science (Newman et al., 2004).

\section{Methodology}

\section{The Grounded Theory Approach}

This study adopts the grounded theory approach. In 1967, Glaser and Strauss established systematic and scientific guides in qualitative methods called "grounded theory" (GT) in contrast to quantitative methods (Dunne, 2011). According to Glaser and Strauss (1967), GT is a research method influenced by symbolic interactionism for developing a theory that conceptualizes the specific social concepts, patterns, and structures through the process of constant comparative methods. GT is interested in knowledge or reality founded in empirical data Johnson \& Christenson, 2012).

This study is based on Glaser's (1998) grounded theory in that the literature review-existing theories of the fieldwas done after collecting data, and integrated into discovered categories from the empirical data to develop and explain properties of the discovered categories and variables. Glaser (1998) claims that these discovered core categories are what legitimize GT work since these core variables open up existing theories and suggest formal and creative aspects of the core variables for future research.

As guided by Gasson's (2004) reflexive grounded theory model, we acknowledge the influence of literature sources in order to build the contextual needs for the existence of the current study as well as our own prior knowledge of the topics. We also recognize the influence of literature sources in developing the conceptual framework in the study. Yet, the literature review related to the main questions was considered as secondary data and was integrated after the core themes of the study were discovered (Gasson, 2004). As a result, the core themes from the first and the secondary data sets are used for the formal theory construction and final interpretation. Table 1 summarizes how three research foci-the nature of learning experiences in an emerging technology activity, perception of integrating emerging technologyinto science teaching, and teaching practices when integrating emerging technology with science-were aligned with the data sources.

\section{Context of The Study}

The two researchers and their membership roles. The first author taught the science methods course as the sole instructor. This study, thus, qualifies as an insider-led workbased study (Costley, Elliot \& Gibbs, 2010). The researcher (1) had certain degrees of control in initiating changes, direction of discussions, and critical inquiry as the main facilitator; (2) was able to practice critical thinking and selfreflection during the investigation; and finally (3) involved elements of personal and professional development for all the participants in the study (Costley, Elliot \& Gibbs, 2010; Reed \& Proctor, 1995). Yet, the researcher's role during the VR activity was limited to that of a peripheral member researcher (Adler \& Adler, 1987; Dwyer \& Buckle, 2009). 
The first author taught the science methods course more than five years. She engaged in continuous curriculum developmental efforts based on her own reflections, outside feedback, and current reform efforts. As a result, revisions and adjustments in the curriculum were made each semester. In addition, the first author engaged in weekly VR activities for two years within the SL platform with a colleague in literature education, optimizing learning experience through a virtual property in the New Media Consortium (NMC) in SL (e.g., CyberTechs, a location for the island: Teaching 2, 179.96.23).
The second author, as an outside member, conducted the literature review alongside the investigation. As noted in grounded theory literature, it is impossible to know beforehand what will emerge from the investigation. Scholars also caution researchers not to be confined by previous theories (Corbin \& Strauss, 2008; Dunne, 2011; Glaser \& Strauss, 1967). As the investigation evolved and relevant concepts emerged from the data, the literature review in this study revealed different aspects. The literature review, as a result, sometimes confirmed findings, but at other times illustrated discrepancies between our findings and existing literature.

Table 1. Summary of the design of the study

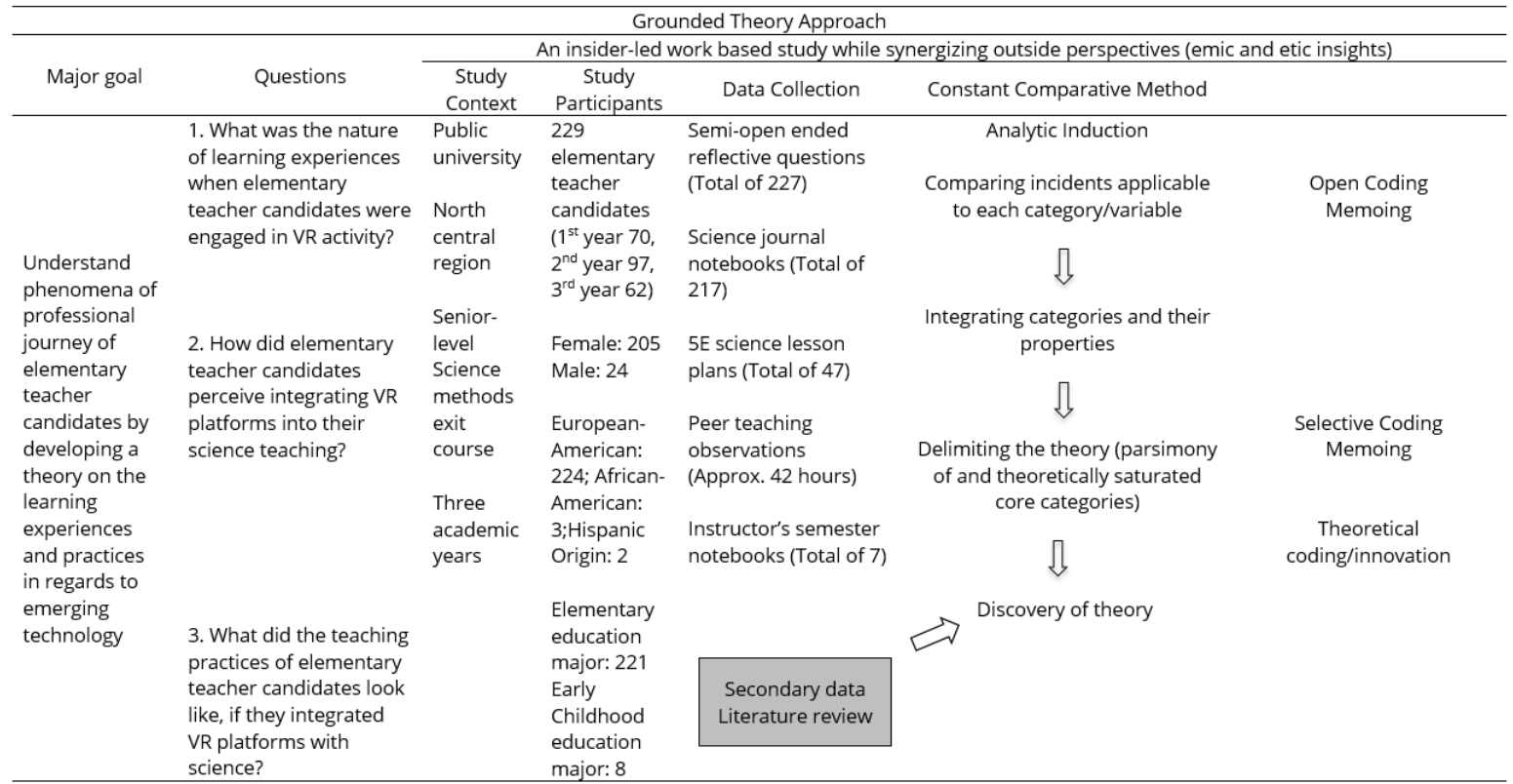

In the process of forming theories, the first author's insider perspective was augmented by the second author's outside point of view, taking advantage of the different memberships brought to the research (Dwyer \& Buckly, 2009). Our two perspectives were reconciled in forming final theories and interpretations.

\section{The Participants}

The participants in the study were all enrolled in a teacher education preparation program in a north central region university in the United States. 229 elementary teacher candidates (ETC) participated in the study over three academic years. There were 24 male and 205 female ETCS involved, the majority coming from a European-American ethnical background (98\%) and majoring in Elementary Education (97\%). Demographic data for the participants are summarized in Table 1

\section{Science methods course}

This is a required exit course for senior level undergraduate students who are enrolled in this elementary and early childhood teacher education program. The course aims to develop ETCs' personal teaching philosophies regarding how students best learn science according to current educational research. The course also emphasizes a practice and reflective approach in order to a) develop a community of active learners, b) learn how to design student-centered and inquiry-based curricula, and c) learn how to evaluate one's own instructional practices.

Disciplinary core ideas include physical sciences, life sciences, and earth and space sciences, along with other concepts such as science as inquiry, scientific and engineering practices, the $5 \mathrm{E}$ model of instruction, as well as science, technology, and society-which were informed by the National Science Education Standards (NAS, 1996). The course content is also influenced by the Framework for K-12 Science Education as well as the Next Generation Science Standards (NGSS) (National Research Council [NRC], 2012).

Weekly activities of this course concentrate on the development of ETCs' pedagogical content knowledge. For example, ETCs engage in learning about assessment, learning environments, curriculum, context, classroom management, the nature of science, and socio-culturalism in the context of teaching science in the $\mathrm{K}-8$ grade levels (Veal \& MaKinster, 1999). Further details on the specifics of the weekly activities of the course can be found in Bang (2013a).

\section{Conceptual Model for Purposeful Activities}

ETCS in this study participated in three purposeful activities: VR activity (Quest: We Are SciTeachers!), 5E 
science lesson plan activity, and peer teaching activity. The activities were designed within the frameworks borrowed from Wenger's (1998) Communities of Practice (COP) and Wells's (2000) dialogic inquiry. Guided by these two frameworks, the activities were then engineered to routinely model Engestrom's (1987) cultural-historical activity theory and Freire's (2003) action and reflection cycle. This conceptual model assumes that the essence of learning is practicing and participating in purposeful activities within the community life and apprenticeship as opposed to the authoritarian tradition of lecturing (Freire, 2003; Holland, Lachicotte, Skinner, \& Cain, 1998; Lave \& Wenger, 1991). The conceptual model also assumes that it is a systematic way to humanize learning and teaching (Freire, 2003).
Learning within the concept of CoP involves recognizing the existence of a community as a shared enterprise and having a set of culture-specific practices. The members in this community actively produce new meaning through negotiations and practices. Successful members, nonmarginalized ones, ultimately become core members of the community while shifting knowledge, skills, roles, motives, cultural capital and tool-kits, values, and identities in practice (Bourdieu, 1986; Wenger, 1998). In addition, learning within the CoP rejects the idea of learning as preplanned, but rather as something that "belongs to the realm of experience and practice" (Wells, 2000; Wenger, 1998, p. 225).

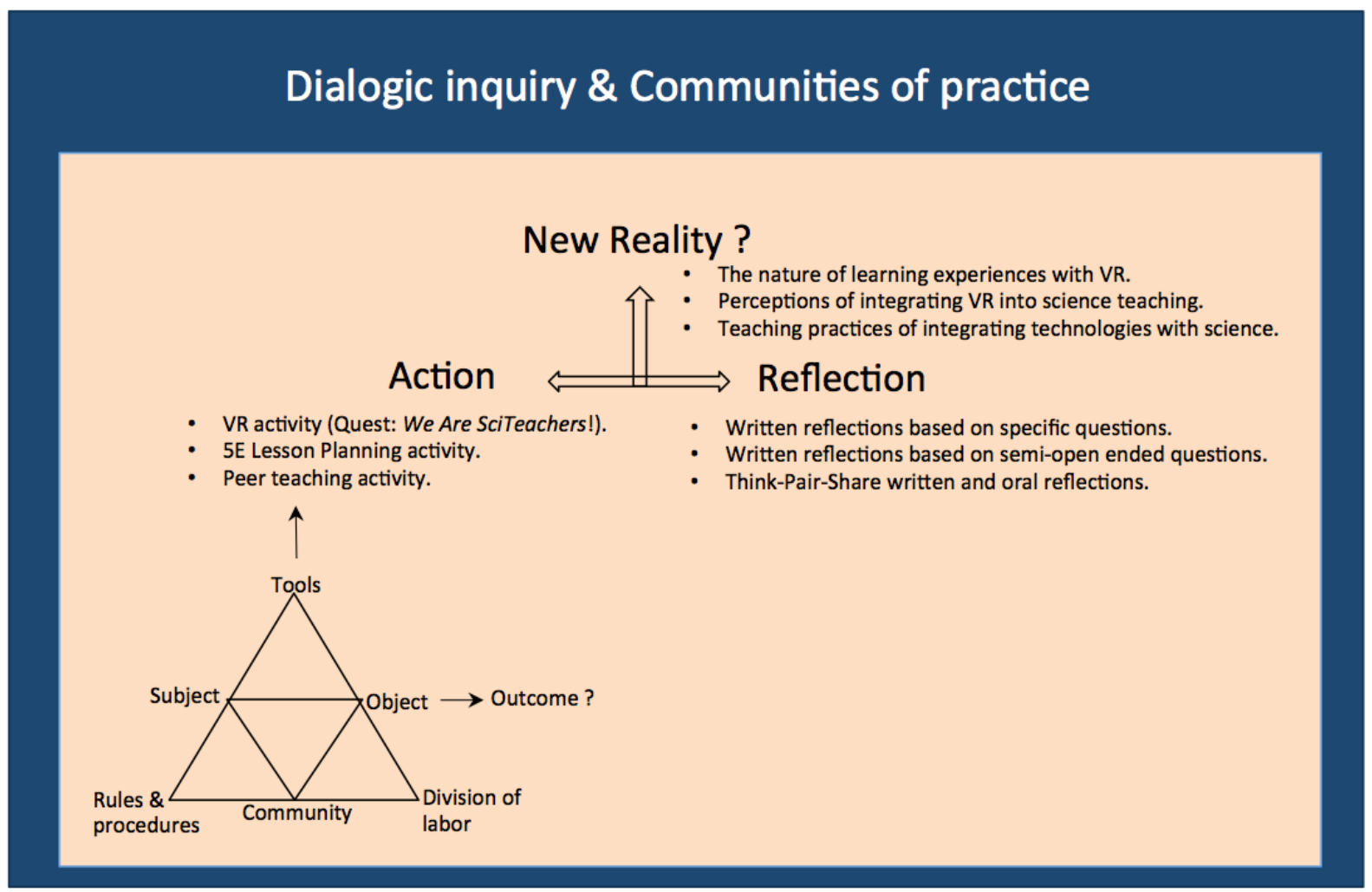

Figure 1. Conceptual model of the purposeful activities situated within the multiple learning theories

The concept of dialogic inquiry, aligned with sociocultural theories, embraces the constructive nature of learning and the learning-by-doing approach that emphasizes intrapersonal-interactive collaborative learning, meaningful experiences, and mentors who follow a scaffolding process (Applefield, Huber, \& Moallem, 2001; Dewey, 1997; Greenfield, 1999; Rogoff, 1990; Vygotsky, 1978). According to Wells (2000), knowledge is built through co-generative discourse. Bakhtin (1986) considers all discourse as dialogic in that it involves generating common understanding, borrowing others' utterances, containing dialogic overtones, and building collective knowledge and constantly producing meaning through various modes of dialogue. Learning in dialogic inquiry, as opposed to didactic instructional methods, regards learning as process, activities as formation of identity, curriculum as a means to engage in activities, and a classroom as a collaborative community (Wells, 2000). Also, learning in dialogic inquiry demands individuals and communities be open to diversity and originality in solving new problems (Wells, 2000).

During the methods course, the ETCS were guided to explicitly and routinely model Engeström's (2000) culturalhistorical activity theory (CHAT) as well as Freire's (2003) action-reflection empowerment cycle. CHAT is originated from Vygotsky's (1978) activity theory and consists of seven elements: subject, object, outcome, instruments/tools, rules, community, and division of labor. According to Engeström (2000), the CHAT framework converges learning organization, knowledge management and social capital. Learning in CHAT means that activities are not only goal-directed but also object-oriented. Therefore, learning activities have coherency and continuity (Engeström, 2000). Yet, these aspects of CHAT generate disturbances and contradictions when deviations from the original scripts occur. Due to these two rather opposing features of 
CHAT, learning in a CHAT context encourages collaborative inquiry, thereby creating a shared vision and collective solutions (Engeström, 2000).

Lastly, Freire's (2003) action-reflection model is adopted to empower ETC to author new realities as a healthy community member and as a self-regulated and critical thinker (Freire, 2003; Wallerstein, 1998). This model promotes knowledge being transformed through lived experiences in order to unveil new knowledge. Learning in the action-reflection cycle promotes development of experiences, critical discovery, openness, and demythologizing knowledge. This model also puts dialogue at the very center of learning and knowing to critically confront reality, and to establish a horizontal relationship among community members (Freire, 2003).

The three purposeful activities: Virtual reality, 5E science lesson plan, and peer teaching activities

The ETCs participating in this study engaged in three purposeful activities related to VR and science teaching over the course of a semester. The common goals which aligned with the conceptual model (see Figure 1) for the three purposeful activities were (a) to develop ETC's capacity as a self-regulated learner and critical thinker through various reflective practices such as selfassessment, self-reflection, and interactions with critical friends within multiple communities of practice; (b) to learn effective methods of science instruction and assessment; and finally, (c) to build a knowledge base about science teaching.

Prior to the three activities, the ETCs were engaged in modeling both the conceptual model (see Figure 1) and the 5 E learning cycle (Bybee et al., 2006). Specifically, they were given multiple learning opportunities to practice how to be an active community member; how to define each other's roles, rules, and procedures in a collaborative learning strategy; and, how to design a 5E science lesson plan using disciplinary core ideas. The ETCs participated in the three activities sequentially over six weeks. ICT tools used during the activities were the following: emails, Blackboard Learn, PBwiki (my.pbworks.com), and Second Life (www.secondlife.com).

Virtual reality activity: QUEST; We Are SciTeachers! This VR activity is designed to develop $21^{\text {st }}$ century skills towards technology, including elements of playfulness, collaborative teamwork, judgment, multitasking, networking, negotiation, a spirit of exploration, and imagination Jenkins, Clinton, Purushotma, Robinson, \& Weigel, 2006). A week before participating in the quest, the ETCs were informed about the main technology platform that was used, called Second Life (SL, www.secondlife.com), a currently available free massively multiplayer online role-playing game (MMORP) program. As a pre-VR activity, the ETCs were individually and along with guidance from the instructor expected to learn the basic features of SL such as safety guidelines, how to create an avatar, and the core rules of netiquette. The instructor first demonstrated her own avatar within the SL platform in terms of how to walk, how to chat, and how to navigate science-related places. Each student explored the SL platform as an avatar once they chose one from the dummy avatars list that contained IDs and passwords. These dummy avatars (female avatars 25, male avatars 5) were provided by the instructor and re-used each semester. Right before the VR activity, the ETCs were given basic guidelines, the science-related places in SL, and the quest sheet, which includes reflection as a post-activity (See Appendix). An alternative activity was also available for those who chose not to participate in the VR activity.

\section{E science lesson plan and peer teaching activity}

These two activities are designed to provide opportunities for ETCS to design and enact the 5E model of instruction collaboratively (Bang, 2013b). As for the pre-activities, the ETCs engaged in the facilitator-modeling inquiry activities to learn how to design and teach science using a $5 \mathrm{E}$ model. These modeling activities were followed by weekly science journal reflections. The ETCS also read selected articles about how to use the $5 \mathrm{E}$ model, engaged in a video case study, and designed a mini $5 E$ lesson. The two tools used during the activities were the Reformed Teaching Observation Protocol (RTOP) (Piburn et al., 2000) and Science Teacher Learning from Lesson Analysis (STeLLA) (Biological Sciences Curriculum Study [BSCS], 2011).

During the lesson plan and classroom enactment period, the ETCs were given $5 \mathrm{E}$ lesson plan guidelines that contained ten items: Introduction, Standards, Objectives, Scientific background, Common misconceptions, Diversity and inclusion strategy, Classroom management, Materials and equipment, Instructional strategy, and a 500-word Individual reflection. The $5 \mathrm{E}$ science lesson plan activity is an evolving and iterative process in that the ETCs, as a team (a group of three or four), participated in outlining, writing a $1^{\text {st }}$ draft, a $2^{\text {nd }}$ draft, and a final draft of their $5 \mathrm{E}$ science lesson plan before their peer teaching. Integrating technology was not a required item for their $5 \mathrm{E}$ lesson planning and teaching but was encouraged through verbal and written feedback. During the peer teaching activity, a group of peer panel members and the first author made observational notes based on RTOP and STeLLA tools while a peer teaching group and the class were engaged in science teaching activities. Peer teaching typically lasted for 50-60 minutes. Right after the peer teaching activities, the whole class was engaged in an in-depth discussion regarding the lesson plan and its implementation, science content taught, classroom culture, 5E sequence, teacher questionings, and/or science content storyline. Finally, each team received a written feedback summary that reflected the comments from the panel members, the first author, and the whole group discussion.

\section{Data Collection}

In this study we collected and analyzed data from five types of data sources: semi-open ended reflective questions, science journal notebooks, 5E science lesson plans, peer teaching classroom observations, and instructor's semester notebooks. The data were collected after ETCS received their final grades. To maintain objectivity and anonymity, three research assistants digitized the raw data and assigned numbers from 1 to 229 for the archived data before the first author and a research assistant began the analysis. 
Both verbally and in writing, the participants were guided to reflect upon their learning experiences right after the VR activity. Four semi-open questions were provided for individual reflection. The participants uploaded these reflections to the class wiki page. Each week, the participants were guided to make half-page journal entries in a composition notebook related to the topics discussed. There were 11 weekly journal entries per semester. A total of 217 of 229 science notebooks were collected, assigned random numbers, scanned, and cataloged in a Microsoft Excel spreadsheet. Twelve science notebooks were removed from our data set due to handwriting illegibility issues or having more than three missing journal entries. As for the data from the VR activity, twenty-two female participants chose not to participate in the activity due to physical dizziness or other personal reasons.

As for the $5 \mathrm{E}$ science lesson plans, only the final drafts were collected (a total of 47 science lesson plans). These science lesson plans were scanned and cataloged in a Microsoft Excel spreadsheet recording targeted events and categories (e.g., Was a technology used or not? If so, why and how was it used? What technology was used and at what stage? Was it used in the $5 \mathrm{E}$ learning cycle?). Approximately 42 hours worth of peer teaching observations were made during the science methods courses by the first author. The first author took field notes while observing peer teaching in the semester notebook describing the ETCs enactments, important components, and questions that arose during the observations (a total of seven notebooks). Finally, these instructor's semester notebooks were used to guide the follow up discussions along the lines of Piburn et al.'s (2000) RTOP and BSCS's (2011) STeLLA tool.

\section{Data Analysis}

The data analysis involved a constant comparative method under the inductive reasoning process. This study followed four steps that were established by Glaser and Strauss (1967) and Gasson's (2004) reflexive GT approach. These systematic analytical steps consisted of (a) open coding for comparing incidents applicable to each category and variable, (b) integrating categories and their properties, (c) selective coding in order to delimit the theory to abide by the rule of parsimony and theoretical saturations of core categories, and finally (d) theoretical coding and a write-up. One of the critical activities used during the process was memoing, which is viewed as a central element in the GT approach (Dunne, 2011; Glaser, 1998). Microsoft Excel spreadsheets and post-it notes were used to color-code and create memos. Finally, the existing relevant literature review was considered as our secondary data and was integrated into findings when examining for the final theoretical construction.

\section{Trustworthiness}

Guided by Shenton's (2004) and Guba's (1981) strategies, this study used multiple data resources in many forms. As a result this study represented multiple voices, had a variety of informants, and therefore reduced the investigator bias (Miles \& Huberman, 1994). For instance, reflective questions and science journal notebook data were individual-based, whereas $5 \mathrm{E}$ science lesson plans and peer teaching observation data were group-based. The instructor's semester notebook data added additional perspective in understanding the phenomena under inquiry. Additionally, data were collected over three academic years; thus, this study used longitudinal data.

To ensure honesty, the participants were allowed to choose an alternative activity during the VR activity. There was no extra credit given for integrating VR platforms into their teaching practices, nor were the participants penalized for not integrating VR platforms into their $5 E$ science lesson plans and peer teachings. The participants were also asked to collect their science journal notebooks once their grades were posted, and were sent email reminders about the study before considering their science journal notebooks as data for this current study. Srivastava and Hopwood's (2009) iterative framework states that "patterns, themes, and categories do not emerge on their own. They are driven by what the inquirer wants to know and how the inquirer interprets what the data are telling her or him" (p.77). Finally, the two researchers integrated both insider (emic) and outsider (etic) perspectives in building a formal theory (Morris, Leung, Ames, \& Lickel, 1999).

\section{Limitations}

Regardless of the efforts made to abide by the rigorousness of the GT approaches, our study was bounded by several limitations in data collection and analysis. For instance, the participants were selected based on purposeful sampling, not random sampling. The participants were not asked to assess the trustworthiness of the data or the results. This absence of member checking may influence the validity of the study. Also, the first researcher's role as an insider and the adopted theoretical lenses may affect the researcher bias in understanding the phenomena. Therefore, what the participants experienced during the study was filtered through the researcher's frames of reference. Finally, there were no systematic measures used to learn about the previous familiarity with the VR platform or with MMRPG, rather the participants reported freely. Due to these limitations, the findings of the study should be understood and applied with discretion.

\section{Results}

Q1. What was the nature of the learning experiences when elementary teacher candidates were engaged in VR activity?

Theme 1: First time VR users learned by playing around as avatars. The ETCs in this study reported that they were first time VR users who had not been exposed to any kind of virtual reality. During this new experience with a 3D digital world, the ETCs started their learning journey with great frustration. The intensity of the ETCs' feelings of difficulty in this VR platform were the highest during the first 10 minutes in SL. During this initial period, the ETCs tried to make their avatars move, walk, dance, fly, or talk at SL Orientation Island where they saw avatars visiting from all over the world. This level of frustration was also evident for those who had some previous experience with Sim Games. Two typical remarks are as follows: 
At first, it was very difficult to find my way around and maneuver my robot [avatar]. As I continued exploring Second Life, I was able to find very interesting icons that allowed me to get around a lot easier [VR reflection $\mathrm{M}$ ID19].

My confidence at first was shattered ... really I didn't understand anything. At first it was very frustrating but after I practiced and gained a little patience then it didn't seem so bad. After this I feel a bit more confident with SL. [VR reflection F-ID6]

The instructor's semester notebook indicated the need for modifying pre-VR activities by having more first-hand experiences with a 3D digital platform. Interestingly, these initial feelings of frustration and difficulty rapidly turned into enjoyable and engaging explorations. The ETCs felt that this was due to the fact that the VR platform allowed them to practice and to gain patience and confidence with SL. After playing around with the program for about 20 minutes, the ETCs started exploring and discovering further interesting features.

Theme 2: First time VR users learned by discovery, by problem solving, or by accident. The ETCs predominantly said that they experienced a true form of discovery and problem solving through the VR activity. Initially, the ETCS as avatars considered SL as an unknown world since they had to learn the language, software features, and rules of engagement. The ETCs as avatars had to play around with many features within the SL program such as how to group chat, how to create an e-note card, how to change the appearance of their avatars, and how to read a mini-map. Also, the ETCs as avatars had to observe their visually intensive 3-dimensional surroundings and make collective or individual decisions on what to do and how to navigate their surroundings in SL. Some described their experience as "figuring things out until you get the hang of things." Representative comments are:

\begin{abstract}
I grew more in my digital skills and confidence by discovering things dealing with Second Life. I still do not feel totally confident using the program because there is so much that goes with using Second Life. [VR reflection F-ID47]

My avatar visited a world whose theme was based on futuristic settings and equipment. Many of the things to do in Second Life cost money but I was able to drive an ATV type vehicle for free. Another aspect that related to science content was investigating the waters and flying through the trees. The visuals are very realistic so it was neat to swim in ponds and the ocean. There were also flowers and plant life but the avatar was unable to physically interact with these things. When first investigating Second Life I had to use inquiry skills such as trial and error or asking experienced avatars how to complete an action or activity. [VR reflection F-ID219]
\end{abstract}

Before the activity, some of the frequently used SL specific vocabularies were reviewed (e.g., avatar, islands, teleport, friendship, object, map, main grid, freeze, prim, machinima, Linden dollar, skin, texture, in-world, and offworld). One comment that illustrates ETCs learning vocabulary terms is "I learned the word teleport to travel to new islands." Teleport is a way for avatars to instantly travel from one island to another. The ETCs were able to understand and use these terms after exploring, or after a lot of trial and error for themselves. In this way, these hands-on activities encouraged rapid learning of SL terms. Some ETCS considered their SL learning experiences similar to inquiry, the 5E learning cycle, or experimentation. Most ETCS valued the learning by discovery that the VR platform offered and recognized that their digital skills had increased.

Theme 3: First time VR users learned science facts and digital skills by social interactions with $3 D$ content and with other avatars. The ETCs navigated science-related islands both as a group and as individuals. In order to function as a team, the ETCs needed to offer and accept each other as friends. This enabled them to instant message, personal chat, and group chat. They could also send each other a teleport invitation. This function can allow any avatar in the friendship list to move instantly to the inviter's island. During this collaborative exploration, they as avatars asked a lot of questions of each other through a nearby chat, a personal chat or a group chat, and suggested some group actions (e.g., I found a cool island! Let me teleport you, Let's fly together to look at the stars in the sky, Let's run to the inside of a stomach). One illustrative comment was:

I was the reporter for our group. My job was to create short memos about each place we went to. It was hard at times because while I was typing the notes my group members would find another great place without me. After we found out how to transport each other then this problem was solved. [VR reflection F-ID28]

Once they teleported to a science-related island, the ETCS actively engaged in deciding what to explore and how to explore the island. Some engaged in conversations with other avatars describing what they were doing with a nearby chat. Some ETCS found this new way of social learning challenging due to the fact that there were so many great places to explore within an island and there were other unknown avatars walking around. Still others initially were unsure of what to do once they teleported themselves to a science-related island. Some ETCs initiated conversations with nearby avatars that were not in their friendship-list when they needed help about how to use some features in SL. Two comments illustrating such social interactions are:

This made me realize that in my three hours of investigating this virtual world, I had only experienced a glimpse, which made the confidence in my virtual reality skill deflate quite a bit. I was, however, proud of the confidence I gained by interacting with other avatars. [VR reflection F-ID32]

We got space suits and saw the moon. This was the first place we landed so we were learning how to communicate with each other and explore [Apollo Moon Landing Island]. We did not think it was very thrilling, so we went to Cloud Chateau. When we arrived we were very confused. We looked around and learned how to sit in chairs. We fell from the cloud and landed on an island and walked on the sea floor. We learned about using angles. ...At Science Friday, we encountered another avatar. We talked to him a little and explored. We saw a penguin but did not figure out how to communicate or do anything with him. We also found that we could teleport by sitting in different chairs. When we teleported to Neil Armstrong Library and Archives, there was a person [an avatar] in the museum to take us to a website. We were able to read articles and learn different historical facts. ... We found some other classmates at 
Virtual Stomach and rode on a Ferris wheel. We found green houses full of peas. You can play a fun chemistry 101 Game on this area... [VR group 34 notecard]

While learning and defining group roles and networking, the ETCS naturally learned digital skills. The ETCs explored their selected science-related islands by looking at different things such as 3D dinosaur models, a spaceflight museum overlooking planet Earth, habitats, weather maps, rockets, or animals. Secondly, the ECTs also engaged in SL by interacting with the 3D objects such as conducting experiments in a laboratory, using a microscope to see cell samples, watching short video clips by clicking a button, asking questions to guides-avatars, or riding on hot air balloons. Finally, the ETCs gathered relevant facts by traversing between 2-dimentional websites and 3dimensional SL. For instance, when a group of the ETCS visited a museum, they were given a button which directly took them to a website link.

Q2. How did elementary teacher candidates perceive integrating VR platforms into their science teaching?

Theme 1: Skeptical integrators (29\%). SL was a frustrating experience. I don't see any merit in using VR platforms. Thus, I wouldn't integrate it into my science teaching. The ETCS in this category demonstrated negative attitudes towards integrating VR platforms into their science teaching. Most of them remarked on the challenging experiences they had with the VR activity. The ETCs in this category disclosed that they did not learn anything scientific, or any new science content, or any useful vocabulary from the VR activity. Three illustrative comments are:

I am unclear about the reasoning why you would incorporate an activity like this in the classroom. [Science Notebook ID8]

I do not think this type of lesson would be useful for my class. I was easily confused about how to operate Second Life \& didn't think it would greatly increase a student's science learning. [VR reflection M-ID5]

I did not learn any new science content and vocabulary from this exploration. I was not able to learn about the places, animals, or innovations I saw through the experience. [VR reflection F-ID047]

Therefore, they disregarded VR platforms as a possible learning and teaching tool for their science classroom. The reasons they provided were diverse. For instance, some were suspicious that the systemic problems they encountered in SL would make them vulnerable to viruses. Some disliked the technical problems with slowly loading images. Some feared that if VR platforms were offered to young learners, they would not be able to have solid guidance control (e.g., inappropriate content, unknown avatars behind the computers). As a result, they predicted that this SL could pose a potential danger for their classrooms.

Theme 2: Observant integrators (59\%). SL was an interesting experience. I see some merit in using $V R$ platforms. Thus, I might integrate VR into my science teaching with some modifications. The ETCS in this category were open to integrating VR platforms into their science teaching only after some modifications are made.
Specifically, the ETCS would surely integrate VR platforms once they practiced a lot more and thought of ways to use it for themselves. Three illustrative comments are:

I think that SL can be used as a resource for a classroom but I would not use it unless I could provide a focused lesson. There are many distractions in this game and my fear would be that they would end up off task. [VR reflection M-ID23]

I would have to have a lot more practice in order to think of ways I would use SL. It's very hard to understand and get around. It reminds me of the Sims a lot.... If I could find a SL for kids then I would use that in my classroom. It would be nice if my class were the only ones in SL. [VR reflection F-ID21]

There are alternative virtual worlds, such as RiverCity, that are made for science investigation of, such as, pollution and over-population. RiverCity is created to make a student the scientist in the world and come up with real life solutions to plausible problems that could happen to cities in the future. As stated before, I could see the potential (if highly monitored and it were impossible to come into contact with unfamiliar avatars) because students could build communities, start businesses and build houses. I look forward to further investigating appropriate, well-monitored virtual worlds that I can apply in my classroom to create a safe learning environment. [VR reflection F-ID90]

The ETCS in this category also noted the importance of finding VR platforms that are appropriate for young learners before incorporating it. Other suggested modifications were a focused science lesson first and less visually intensive VR platforms (e.g., class-only or gradelevel-only VR platforms). They reasoned that these modifications would prevent students from being distracted or going off-task in their classrooms. The ETCs in this group embraced the initial challenges that they had with SL and valued its features such as interacting with others and with 3D digital worlds as resource and education tools.

Theme 3: Innovative integrators (12\%). SL was a fun experience. I see great merit in using VR platforms. Thus, I will definitely integrate $V R$ into my science teaching. The ETCs in this category were enthusiastic about integrating VR platforms into their science teaching. Their reflections indicated much excitement on exploring $S L$ and a desire to try new things along with VR technology, features, and designs. The ETCS considered VR platforms as great mediating tools for young learners to explore on their own, similar to the way they learned it by discovery and social interactions. In integrating VR platforms, the ETCS imagined themselves allowing their students to navigate to new places that were interesting to them and conduct their own learning. Some also perceived that VR platforms would be a great way to show their students the spontaneity and fun in exploration. Three illustrative comments are:

Once we got into the virtual reality tour, we were able to find many virtual rooms and buildings such as the aquarium and the dinosaur center. It was really fun observing all the areas and becoming more knowledgeable on these subjects. This would be a great way for students to observe and experiment with these 
science related subjects, or also to introduce/become familiar with 5E. [VR reflection M-ID12]

This may make science more interesting for children as they would be allowed to play games. They could possibly learn some information in an interesting way if they stopped to read the posted signs throughout the game...[VR reflection M-ID14]

While using Second Life I learned how to control and navigate my avatar. There are many possibilities of places to travel. There are videos and simulations that you can show your class. If used effectively it could be beneficial to help teach students a topic. [Group8 note card]

The ETCS indicated that VR platforms would be a motivational tool to make science more interesting. For instance, students first could learn how to control and navigate their avatars, and then play games while traveling to and taking photos of many different places. As a teacher integrating VR platforms, they illustrated that they would show videos and simulations to their students when learning about science topics. They would also search for helpful teacher resources within VR platforms that would lead them to $2 \mathrm{D}$ websites. Within the $5 \mathrm{E}$ model of instruction, some indicated that they would use VR platforms only after their students had acquired first-hand experience and explicitly learned about the scientific concepts.

Q3. What did the teaching practices of elementary teacher candidates look like when they integrated VR platforms with science?

The ETCS seldom integrated technology with science during their teaching practices and rarely mentioned it in their science journal notebooks (only $4 \%$ of the notebook entries). When prompted on technology integration, the ETCs mentioned computers, Internet, websites, ELMO, and videos as their technology tools for science teaching. Furthermore, none of the ETCs in the study integrated VR platforms into their $5 \mathrm{E}$ science lesson planning or peer teaching, as illustrated in these excerpts from two lesson plans:

Explore: The students will research about tadpoles and complete the "FACT" sheet (Including: habitat, what they eat, lifecycle, etc.) [5E science lesson plan ID8: The lifecycle of a tadpole, $3^{\text {rd }}$ grade]

During the engagement stage, Teacher will introduce topic: "Today we are going to talk a little bit about volcanoes. What do we know about volcanoes? Has anyone seen a volcano erupt before? We are going to take a look." Teacher pulls up YouTube videos listed under materials. The overall purpose of these videos is to get students interested in finding out why volcanic eruptions differ in power and lava flow speed. Students watch and observe them, writing down observations and inferences in a chart format. [5E science lesson plan ID33: Volcanoes, $5^{\text {th }}$ grade]

In addition to a complete absence of VR integration, only $29 \%$ of the $5 E$ teams integrated some type of technology, specifically websites, short video clips, or computers. For instance, the ETCs used teacher pre-screened websites for student research activities mostly during the exploration or elaboration stage. Short video clips were also used for motivating students during the engagement stage or to define major terms during the explanation stage (e.g., phases of the Moon, volcanoes).

\section{Convergence of Results with Related Literature}

We conducted the literature review, in part, to further understand our findings from the analysis and, in part, to validate and refine what we found (Corbin \& Strauss, 2008; Dunne, 2011). The findings from the analysis revealed the journey of ETCs from a learner of science in a VR activity to a science teacher using VR. As a result, we focused our literature review in three areas, which helped us interpret the analysis results and strengthen our understanding of ETCs' journey from learners to teachers of emerging technologies. The three focus areas included: (a) learning science through emerging technologies in elementary classrooms, (b) learning barriers, experiences, and challenges in integrating technologies into instruction, and (c) preparing elementary science teachers to integrate emerging technologies. Our study specifically focused on ETCs' use of Second Life, which is one of many emerging technologies. When searching for relevant literature, we did not limit the literature to Second Life, in part because we wanted to interpret the findings against a broader backdrop and in part because there is limited research on Second Life in an elementary setting. Figure 2 illustrates the convergence of the major findings of this study with those in the related literature.

\section{Learning science through emerging technologies in elementary classrooms}

We were first interested in the use of emerging technologies in elementary science classrooms. When ETCs go out to classrooms, what kind of classrooms would they face? To what extent do teachers use emerging technologies in elementary science classrooms? Reviewing technology use in instruction, Lawless and Pellegrino (2007) stated, "The resources and environments in which teachers and students were expected to use technology prior to 1999 are no longer analogous to current standards" (p. 584). There is, indeed, a wide variety of new and innovative technologies integrated into elementary classrooms nowadays. Video games, augmented reality, and 3D virtual worlds are representative examples of emerging technologies introduced in elementary classrooms.

Several studies reported positive gains through educational video games (Burguillo, 2010; Liu \& Chu, 2010). In elementary classrooms, Annetta, Mangrum, Holmes, Collazo, and Cheng (2009) investigated fifth graders' learning of simple machines using a gaming application. They identified gender differences in the time spent for computer and video games. They also reported high student engagement and learning achievements. Inservice elementary teachers in a hybrid-mentoring program also reported that emerging technologies, such as various science applications using handheld digital devices, were guaranteed motivational learning tools for their students (Bang, 2013b). Sung and Hwang (2013), focusing on collaborative learning, facilitated Taiwanese sixth graders' sharing and organizing what they had learned with a game-based learning environment called Mindtool. Participating sixth graders improved not only in 
attitude and motivation, but also in learning achievements and self-efficacy.

Scholars also identified augmented reality for its potential to enhance learning experiences ( $\mathrm{Wu}$, Lee, Chang, \& Liang, 2013). Augmented reality provides interactive experiences in a 3D space, but, unlike 3D virtual words where participants are immersed in the 3D environments, augmented reality sits in between real and virtual worlds. Kerawalla, Luckin, Seljeflot, and Woolard (2006) used augmented reality to teach about the Earth, Sun, and day- night cycle to 10-year-olds in the United Kingdom. They identified the potential for augmented reality in educational settings; however, they found that the use of augmented reality did not improve upon a role-playing lesson. Teachers participating in the study also asked for more flexible and controllable materials. Applying augmented reality in an elementary library, Chen and Tsai (2012) reported an improvement in the students' learning performance. They found no gender differences, as compared to conventional librarian instruction.

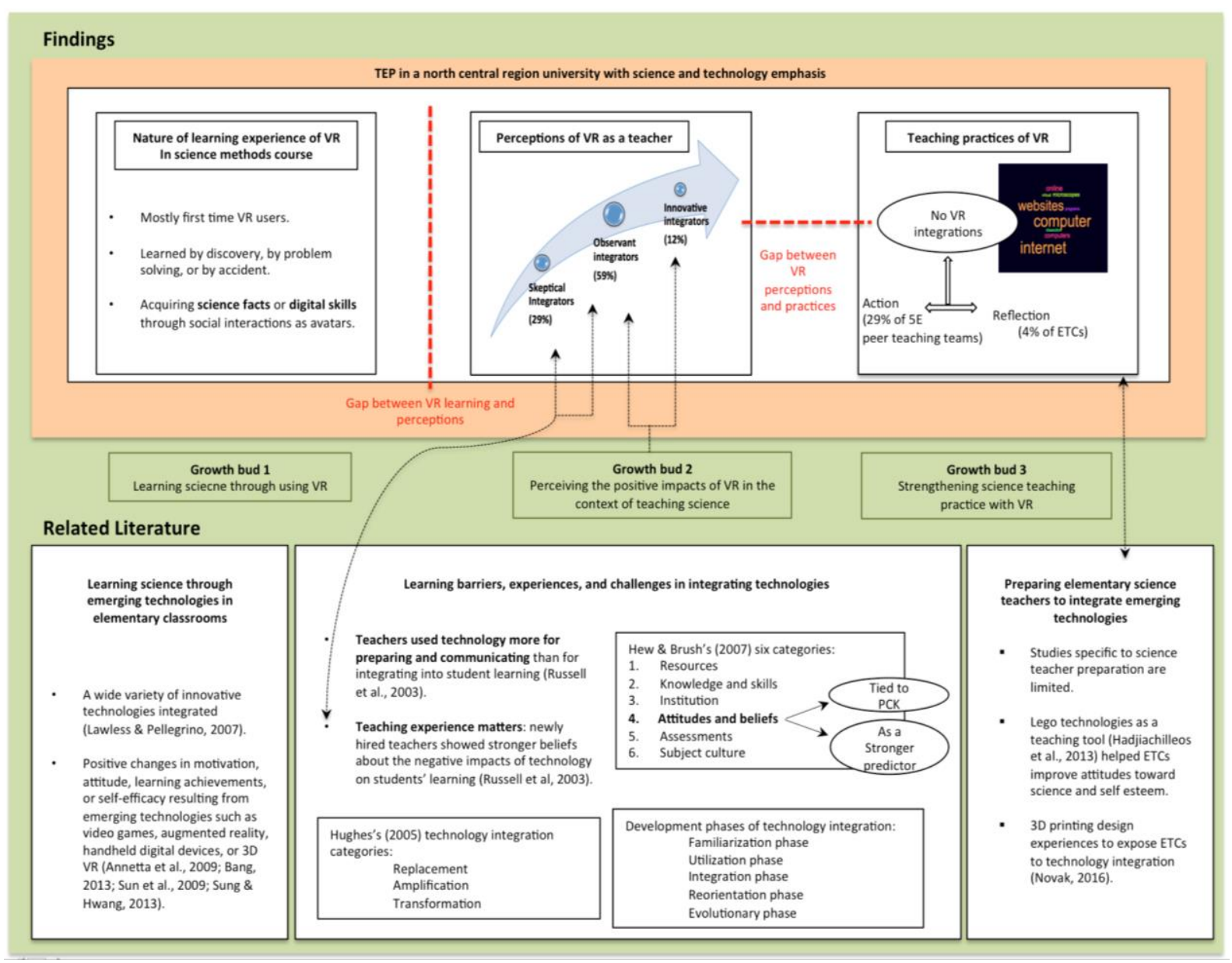

Figure 2. Convergence of the major findings of this study with the related literature.

$3 \mathrm{D}$ virtual worlds were used to teach plate tectonics to fifth graders (Kim, 2006) and the solar system (Sun, Lin, \& Wang, 2010) to Taiwanese fourth graders. Both studies reported higher learning achievements in the 3D groups compared to the control groups. Kim (2006) noted no gender or ethnicity differences in either achievement tests or attitude. SL is often categorized as a 3D virtual world. We, however, had a hard time locating a study using SL in elementary science instruction. Reviewing the research using SL in an educational setting, Inman, Wright, and Hartman (2011) noted that the majority of studies took place in higher education.

Based on the review of emerging technology use in elementary classrooms, we argue that although the research evidence is not sufficient for effectiveness in academic achievement, it is safe to say that various emerging technologies are integrated into elementary science classrooms. The potential of 3D virtual worlds, with their open-ended environments, interactive social tools, and 3D space, also seems promising.

\section{Learning barriers, experiences, and challenges in integrating technologies}

When considering emerging technology for instruction, what hinders teachers from using it? Reviewing 48 studies on K-12 technology integration, Hew and Brush (2007) identified a total of 123 barriers that hinder technology integration into instruction and classified them into six categories: (a) resources, (b) knowledge and skills, (c) institution, (d) attitudes and beliefs, (e) assessment, and ( $f$ ) subject culture. Of these six, teacher attitudes and beliefs are the most relevant to the findings of this study. Teacher 
attitudes and beliefs are known to be one of the major barriers to integrating technologies into classroom instruction (Ertmer, 2005; Hermans, Tondeur, Van Braak, \& Valcke, 2008). Teacher attitudes and beliefs shape their goals for technology use (Ertmer, Addison, Lane, Ross, \& Woods, 1999), affecting the frequency and degree of technology use in instruction. Hew and Brush (2007) argue that teacher attitudes and beliefs influence technology integration more directly, compared to other elements such as subject culture, assessment, and institution. Teacher attitudes and beliefs towards technology are tied to "a teacher's understanding of pedagogy (i.e. pedagogical content knowledge) and to how these various technologies can facilitate learning and achievement among students, and how to assess the various outcomes of learning in these contexts" (Lawless \& Pellegrino, p.596).

Teachers' use of technology is also related to teaching experience. Analyzing surveys from 2,894 teachers in 22 Massachusetts districts, Russell, Bebell, O'Dwayer, and O'Connor (2003) found that teachers used technology more often for preparing and communicating than for engaging students in learning activities. In addition, they found that novice teachers (with less than five years of teaching experience) used technology in instruction less than more experienced teachers, although novice teachers demonstrated higher comfort levels with technology. This study also noted, "Teacher beliefs about the importance of technology for teaching was the strongest predictor of the frequency with which technology is used for a given purpose" (p. 302). Novice teachers expressed significantly stronger beliefs about the negative impacts of technology on students learning. Novice teachers, in other words, were less confident that technology would have a positive impact on students in instructional environments, though they used technology to prepare instruction. The negative impacts included, "Making students more lazy, decreasing research skills, and decreasing the quality of student writing" (p.305). ETCs in this study quickly mastered how to navigate and learn science in VR platforms; yet they might not have seen the importance of VR platforms for teaching science.

The research on the stages of technology integration also helps us interpret our analysis results. Stages of technology integration have emphasized the differences and changes in teachers' use of technology; several models of technology integration are available (Toledo, 2005). These stages are not specific to emerging technologies; yet, they do provide insights into how teachers might use emerging technologies in designing and implementing classroom instruction. Types of technology use can be categorized as replacement, amplification, and transformation (Hughes, 2005), each serving different instructional purposes. Further development phases of technology integration include (a) familiarization, (b) utilization, (c) integration, (d) reorientation, and (e) evolutionary phase, although wordings differ slightly per study. The ETCs in this study were familiar with how SL worked, and were able to utilize the technology to perform the quest. However, they fell short by failing to integrate technology into their instruction when they could have used technologies to provide a rich context for students' understanding of pertinent concepts, themes, and processes (Moersch, 1995; Toledo, 2005). The ETCs in this study neither fully reached the integration phase nor moved on to the reorientation or evolutionary phases.

Preparing elementary science teachers to integrate emerging technologies

Finally, we reviewed literature on the preparation of elementary science teachers for technology integration. As access to technologies in classrooms increases, greater emphasis has been placed on preparing elementary teachers to use technology for science education (NAS, 2010). Various methods have been employed either to increase pre-service teachers' knowledge and skills in emerging technologies or to improve pre-service teachers' attitudes towards the use of technologies in instruction. Hadjiachilleos, Avraamidou, and Papastavrou (2013) used Lego Technologies as a teaching tool for pre-service teachers and observed their development in both cognitive and non-cognitive domains. Pre-service teachers in the study demonstrated engagement with the Lego activities and were able "to overcome non-cognitive factors that often impede science learning outcomes such as gender issues, prior experiences, and attitudes toward science and self-esteem" (p. 627). Novak and Wisdom (2016) provided pre-service teachers with hands-on 3D printing design experiences to expose them to technology integration and to increase their engagement in science. Based on the analysis results they recommended 3D printing projects in elementary teacher science methods courses. Although studies exploring elementary teacher preparation in the use of technology are burgeoning, studies specific to science instruction are limited.

Few studies exist about elementary science teacher preparation for technology integration. However, scholars argue that "decisions about when to use technology, what technology to use, and for what purposes cannot be made in isolation of theories and research on learning, instruction, and assessment." (Lawless \& Pellegrino, 2007, p. 581). This suggests that science teachers' preparation and their use of technologies are closely linked to goals, scientific inquiries, and assessments. Marino, Israel, Beecher, and Basham (2013) reported, after investigating middle school students' use of video games, that teachers who participated in the study thought that the video games linked to national science benchmarks, and assessments within games had more promise. Connecting technologies to science planning and instructional implementation and making more explicit technology integration efforts in teacher preparation are an area in need of more research. Kay (2006) concluded, for example, after reviewing 68 studies in technology integration in pre-service education, that collaboration among teacher preparation, including mentor teachers, is critical to improving abilities and attitudes towards the meaningful use of technology. More explicit, sustained, collaborative, and systematics efforts are needed to increase the chances for successful technology integration.

\section{Discussion and Implications}

The goal of this study was to understand the several phenomena of the professional journey of ETCs who were near the end of a teacher education program. Within the 
context of a science methods course, this study examined ETCs' learning science and learning-to-teach science with a focus on a particular emerging technology, SL. The main curriculum, activities, and instructional materials of this evolving science methods course were designed to embody the concepts from Communities of Practice (Wenger, 1998) and Dialogic Inquiry (Wells, 2000) (See Figure 1).

The results of this study, which were compared and contrasted with the relevant literature reviews, revealed two gaps and three areas of growth, as shown in Figure 2. The first gap indicated the contrast between the positive learning experiences of the majority of the ETCS and the small number that stated they would use VR in their science teaching (Innovative integrators, 12\%). The second gap pointed to a further contrast between the ETCS who noticed the positive impacts of using VR in their science teaching (both observant and innovative integrators, 71\%) and their actual teaching practices, including lesson plans, peer teaching, and reflections, which showed little evidence of VR integration with science teaching.

Based on the gap analysis, we propose three areas of growth, which we identify as growth buds. Growth buds are where ETCs might develop their understanding of science and technology and grow to become science teachers. Growth bud 1 is related to providing ETCs with continuous opportunities to learn science and digital citizenship through emerging technologies. Growth bud 2 is associated with supporting ETCs to see themselves as innovative integrators in the context of teaching science and emerging technologies. Growth bud 3 involves strengthening ETCs' science teaching orientations (Friedrichsen et al., 2009) and teaching repertoires with emerging technologies.

In growth bud 1, the ETCs, as learners of science and emerging technology, considered the VR experience similar to inquiry-based learner-centered activities that follow the natural processes of scientific inquiry. Some ETCS believed that they had experienced a true form of self-discovery learning. Our data showed that the intense $3 \mathrm{D}$ visual objects and 3D science-related content motivated the ETCs to read more about scientific facts. Our data also indicated that the ETCs acquired digital skills while participating in the SL activity (e.g., learning how to use SL chats, e-notes, learning SL specific terms, learning which tool to use to teleport to islands). Therefore, the SL VR platform provided a unique learning experience for the ETCs who were projected as avatars in a 3D virtual world. Yet, some details found within these results require further consideration on how to guide ETCs to foster in-depth science learning and to cultivate mature digital citizenship along with various VR platforms or other emerging educational technologies (e.g., 3D printing technology, augmented reality, handheld digital devices).

In growth bud 2, the ETCs began to transform from their roles as undergraduate students to teachers who examine VR as an instructional material. As science teachers, $71 \%$ of the ETCs were willing to try integrating VR into their teaching. Yet, both the skeptical integrators (29\%) and the observant integrators (59\%) expressed great-to-moderate levels of negative attitudes towards using VR in their science teaching. This solidifies the findings from Russell et al.'s study (2003), where novice teachers were more reluctant to integrate technology into instruction although they had more technology knowledge and skills than experienced teachers.

Growth bud 2 is situated within this transitional space where ETCs shift from participating as learners of science to thinking like teachers. This is also the place where we expected that ETCS would channel their positive experiences as learners of VR into perceiving themselves as active users of VR to teach science. This process, however, was not as natural as expected for most participants. Few ETCs noticed affordances of VR for young learners and consequently did not see the merit of using VR in science instruction.

In growth bud 3, where ETCs engaged in designing and enacting science lessons, ETCs showed little interest in science phenomena represented in the 3D worlds and rarely engaged in discussing these phenomena in relation to goals, assessment or instructional strategies. This observation supports the findings from the existing literature, which indicate that teachers' perceptions towards technologies play a great role in their implementation of technologies. We conjecture that the negative attitudes that ETCs associated with VR affected their instructional decisions, which is evident in their $5 \mathrm{E}$ lesson plans and peer teaching. None of the ECTs used or integrated VR during their peer teaching. In addition, the use of other technologies was also limited. Only $29 \%$ of the $5 E$ peer teaching teams incorporated technology, and only $4 \%$ of the ETCs mentioned any type of technology integration in their science notebooks. The technology they utilized was limited to computers, websites, or the Internet, which was used to research or find scientific facts for learners. In growth bud 3, ETCs need to further develop and strengthen pedagogical content knowledge. This is also the area for establishing, modeling, and practicing meaningful integration of technologies.

Overall, this study delineated ETCs' professional journey from learning science through VR to practicing innovation in science instruction. By analyzing the multiple types of data collected, interpreting the results, and reviewing the relevant literature, we were able to identify three phases of the journey and specific challenges that the ETCS faced at each phase of the journey (see Figure 2). Addressing the challenges identified in this study will help facilitate ETCs' professional journey into becoming successful elementary teachers.

The first challenge is that ETCs' positive learning experiences with VR did not naturally translate into willingness to use VR in science instruction. Skeptical integrators did not perceive themselves integrating VR into their science teaching. This could have resulted from the fact that the ETCS in the study were mostly first time VR users. Teacher preparation should address this lack of familiarity more explicitly and intently. As shown in Hughes's (2005) and others' development phases of technology integration, we learn that teachers go through the phases of familiarization and utilization before the integration phase. More sustained learning experiences in methods courses and possibly extended and collaborative 
experiences in field placement will increase ETCs' knowledge and familiarity with emerging technologies.

Another challenge is situated in growth bud 3, where even the most advanced participants did not integrate VR into their science teaching. There are few studies on emerging technology integration within the context of elementary science methods courses; therefore, there was little that we could glean from existing literature on how to assist ETCs crossing this second challenge. Yet, based on our analysis of the results and the existing literature on general teacher preparation, we propose that we need to approach this challenge by systemizing ETCs' learning experiences and explicitly developing ETC's perceptions as teachers.

According to the International Society for Technology in Education, educators are positioned as learners, leaders, citizens, collaborators, designers, facilitators, and analysts. Also, learning science involves ETCs developing an in-depth understanding of the nature of science by actively exposing their misconceptions about the scientific worldview, scientific inquiry, and scientific enterprise (American Association for the Advancement of Science, 1990). During their 90-minute immersion in the VR world, the ETCs experienced a type of learning that was practical and exploratory. We consider this first-hand positive experience to be the very first requirement for the ETCs to be able to effectively fulfill their roles as learners, leaders, and citizens of the ICT.

However, the ETCs in our study did not maximize the experiences that this particular learning environment afforded. The majority of the ETCs had individualized experiences in the 3D environment. For example, they read about scientific facts from island to island, or interacted with the 3D contents either alone or with a small number of other avatars. Some ETCs were unsure of what to explore and how to explore; thus, they, as avatars, simply followed the other active avatars. The 3D world opens up hybrid space where ETCs might practice their identities as teachers of science. Yet, the significance of using avatars as projecting idealized selves was barely present in this study. In addition, they established only weak connections with their avatars for the purpose of practicing, visualizing, and internalizing professional identities. This link should be addressed in a more explicit manner in the methods course to help ETCs transition from a learner of science to a successful science teacher.

We also propose explicit and purposeful learner-centered pre- and post-VR activities. Initial VR activities may aim to engage ETCs to learn about technology, to learn about the features of the targeted technology, to learn how to present themselves as avatars, and the like. ETCs also need time to engage in activities that can develop connections with their projected-avatars (e.g., creating one's own avatar, collecting personal inventory items to express desired appearances and behaviors). After these prestages are explored, ETCs may be guided to explore how to maximize VR learning environments and how to identify science learning goals. During this phase, ETCs act-like, talk-like, and feel-like scientists and, therefore, become active learners of science. Post-activities should teach the ETCS how to meaningfully transfer their VR learning experiences into their teaching practices.
This study indicated that ETCs were not familiar with emerging technologies and faced challenges when designing and implementing science lessons that integrated emerging technologies. Yet, because of the unexpectedness and openness of the emerging technologies, VR provides a good place to learn about what it means to live in a digital world, to mature into a digital citizen, and to develop an appreciation for working within ambiguous contexts. Emerging technologies hold a high promise to enhance science learning and the ETCs' digital citizenship. Learning science is much more than just learning facts about science. A 3D world, such as SL, provides a unique learning space and a mode for future elementary science teachers to experience and practice science. Further, ETCs can safely design, practice, and experience science teaching in learner-centered, exploratory, and interdisciplinary environments and complete their journeys from learners to teachers.

\section{Acknowledgements}

We thank the elementary teacher candidates who participated in our study. We also thank Rhonda Berry, Sara Nelson and Jennifer Smith for their assistance during the process of making the collected data anonymous, systematized, and organized. We have benefited from Gauri Ramasubramanian for her yearlong assistance in cataloging the scanned data. Finally, we are grateful to Dr. Frankie S. Laanan, interim director of the Center for Excellence in Science, Mathematics, and Engineering Education at lowa State University, and to Dr. John Hauptman for their support and encouragement.

\section{References}

Adler, P., \& Adler, P. (1987). Membership roles in field research. Newbury Park, CA: Sage.

American Association for the Advancement of Science (AAAS). (1990). Project 2061: Science for all Americans. New York: Oxford University Press.

Applefield, J., Huber, R, \& Moallem, M. (2001). Constructivism in theory and practice: Towards better understanding. The High School Journal, (Dec.-Jan.) 3553.

Annetta, L., Mangrum, J., Holmes, S., Collazo, K., \& Cheng, M. (2009). Bridging reality to virtual reality: Investigating gender effect and student engagement on learning through video game play in an elementary school classroom. International Journal of Science Education, 31(8), 1091-1113.

Bang, E. (2013a). Exploring impact of the EED 420 Science Methods Course on pre-service elementary teachers views regarding the nature of science. International Electronic Journal of Elementary Education, 5(3), 219232.

Bang, E. (2013b). Hybrid-mentoring programs for beginning elementary science teachers. International Journal of Education in Mathematics, Science and Technology, 1(1), 1-15.

Bakhtin, M. M. (1986). Speech genres and other late essays. (Y. McGee, Trans.). Austin: University of Texas Press. 
Biological Sciences Curriculum Study (2011). Science teachers learning through lesson analysis (STeLLA). Retrieved from https://bscs.org/stella.

Bleicher, R. E. (2006). Nurturing confidence in pre-service elementary science teachers. Journal of Science Teacher Education, 17, 165-187.

Bourdieu, P. (1986) The forms of capital. In J. Richardson (Ed.) Handbook of Theory and Research for the Sociology of Education (New York, Greenwood), 241258.

Burguillo, J. C. (2010). Using game theory and competitionbased learning to stimulate student motivation and performance. Computers \& Education, 55(2), 566-575.

Bybee, R.W., Taylor, J.A., Gardner A., Scotter, P.V., Powell, J.C., Westbrook, A. \& Landes, N. (2006). The BSCS 5E instructional model: Origins and effectiveness. Retrieved from, https://bscs.org/sites/default/files/ _media/about/downloads/BSCS_5E_Full_Report.pdf

California Council on Science and Technology. (2007). Critical path analysis of California's science and mathematics teacher preparation system. Retrieved from, http://www.google.com/url?sa=t\&rct=j\&q=\&es $r c=s \&$ so urce $=$ web\& $c d=4 \& v e d=0 C D k Q F j A D \&$ url=http:// www.cftl.org/documents/2007/TCPA.pdf\&ei=UAw3Upa _K6PO2wXspYDACQ\&usg=AFQjCNGFfOIAjpq-zcb5oVps BdiUnWq69A\&bvm=bv.52164340,d.b21

Chen, C. \& Tsai, Y. (2012). Interactive augmented reality system for enhancing library instruction in elementary schools. Computers \& Education, 59(2), 638-652.

Corbin, J. M., \& Strauss, A. L. (2008). Basics of qualitative research: Techniques and procedures for developing grounded theory. Sage Publications, Inc.

Costley, C., Elliott, G., \& Gibbs, P. (2010). Doing work based research: Approaches to enquiry for insiderresearchers. London, English: SAGE Publications Ltd.

Crowther, D. T., \& Bonnstetter, R. J. (1997), Science experiences and attitudes of elementary education majors as they experience Biology 295: A multiple case study and substantive theory. Proceedings of the annual International Conference of the National Association for Research in Science Teaching (ERIC Document Reproduction Service No. ED 405220).

Dewey, J. (1997). How We Think. Dover Publications: Mineola NY.

diSessa, A. (2000). Changing minds: Computers, learning, and literacy. Cambridge, MA: MIT Press.

Dunne, C. (2011). The place of the literature review in grounded theory research. International Journal of Social Research Methodology, 14(2), 111-124.

Dwyer, S. C., \& Buckle, J. L. (2009). The space between: On being an insider-outsider in qualitative research. International Journal of Qualitative Methods, 8(1), 5463.
Engeström, Y. (1987). Comment on Blackler et al activity theory and the social construction of knowledge: a story of four umpires. Organization-The Interdisciplinary Journal of Organisation, Theory and Society Studies, 72), May 2000, 301-310.

Friedman, T. L. (2005). The world is flat: A brief history of the twenty-first century. New York: Farrar, Straus and Giroux.

Ertmer, P. A. (2005). Teacher pedagogical beliefs: The final frontier in our quest for technology integration? Educational Technology Research and Development, 53(4), 25-39.

Ertmer, P. A., Addison, P., Lane, M., Ross, E., \& Woods, D. (1999). Examining teachers' beliefs about the role of technology in the elementary classroom. Journal of Research on Computing in Education, 32(1), 54-71.

Freire, P. (2003). Pedagogy of the oppressed. New York: Herder and Herder.

Friedrichsen P. J., Abell S. K., Pareja E. M., Brown P. L., Lankford D. M., Volkmann M. J. (2009). Does teaching experience matter? Examining biology teachers' prior knowledge for teaching in an alternative certification program. Journal of Research in Science Teaching, 46(4), 357-383.

Gasson, S. (2004). Rigor in grounded theory research: An interpretive perspective on generating theory from qualitative field studies. In M. E. Whitman \& A. B. Woszczynski (Eds.), The handbook of information systems research (pp. 79-102). Hershey, PA: Idea Group.

Glaser, B. G. \& Strauss, A. L. (1967). The discovery of grounded theory: Strategies for qualitative research. New Brunswick, New Jersey: Aldine Transaction.

Glaser, B.G. (1998). Doing grounded theory: Issues and discussions. Mill Valley, CA: Sociology Press.

Greenfield, P.M. (1999). Historical change and cognitive change: A two-decade follow-up study in Zinacantan, a Maya community in Chiapas, Mexico. Mind, culture, and activity, 6(2), 92-108.

Guba, E.G. (1981). Criteria for assessing the trustworthiness of naturalistic inquiries, Educational Communication and Technology, (29), 75-91.

Hadjiachilleos, S., Avraamidou, L., \& Papastavrou, S. (2013). The use of Lego technologies in elementary teacher preparation. Journal of Science Education and Technology, 22(5), 614-629. DOI 10.1007/s10956-0129418-4

Hermans, R., Tondeur, J., van Braak, J., \& Valcke, M. (2008). The impact of primary school teachers' educational beliefs on the classroom use of computers. Computers \& Education, 51(4), 1499-1509.

Hew, K. F. \& Brush, T. (2007). Integrating technology into K12 teaching and learning: Current knowledge gaps and recommendations for future research. Educational Technology Research Development, 55(3), 223-252. 
Holland, D., W. Lachicotte, D. Skinner, and C. Cain. (1998). Identity and agency in cultural worlds. Cambridge, MA.: Harvard University Press.

Hughes, J. E. (2005). The role of teacher knowledge and learning experiences in forming technology-integrated pedagogy. Journal of Technology and Teacher Education, 13(2), 277-302.

Inman, C., Wright, V. H., \& Hartman, J. A. (2011). Use of Second Life in K-12 and higher education: A review of research. Turkish Online Journal of Distance Education, 12(3), 67-85.

Jenkins, H., Clinton, K., Purushotma, R., Robinson, A. J., \& Weigel, M. (2006). Confronting the challenges of participatory culture: Media education for the 21st century. Chicago, IL: MacArthur

Johnson, B., \& Christensen, L. (2012). Educational research: Quantitative, qualitative, and mixed approaches. (4th ed.). Thousand Oaks, California: SAGE Publications Ltd.

Kay, R. H. (2006). Evaluating strategies used to incorporate technology into preservice education: A review of the literature. Journal of Research on Technology in Education, 38(4), 385-410.

Kerawalla, L., Luckin, R., Seljeflot, S., \& Woolard, A. (2006). "Making it real": Exploring the potential of augmented reality for teaching primary school science. Virtual Reality, 10, 163-174.

Kim, P., (2006). Effects of 3D virtual reality of plate tectonics on fifth grade students' achievement and attitude toward science. Interactive Learning Environments, 14(1), 25-34.

Kleiner, B., Thomas, N., Lewis, L., \& Greene, B. (2007). Educational technology in teacher education programs for initial licensure: Statistical analysis report. (Master's thesis), Available from U.S. Department of Education. (NCES 2008-040). Retrieved from http://www.google.com/url?sa=t\&rct=j\&q=\&esrc=s\&so urce $=$ web \&cd $=2 \&$ ved $=0 C D o Q F j A B \& u r l=h t t p: / /$ nces.ed. gov/pubs2008/2008040.pdf\&ei=AQ83UrjfLoS22AX8wY HYCw\&usg=AFQjCNFiLzihpzFPaDXUUkOdXf6JRhtewg\& bvm=bv.52164340,d.b21

Kuenzi, J. J. (2008). STEM (science, technology, engineering and mathematics) education: Background, federal policy and legislative action. CRS report for Congress. Retrieved from http://www.fas.org/sgp/crs/misc/RL33434.pdf

Lave, J. \& Wenger, E. (1991). Situated Learning: Legitimate Peripheral Participation. London: Cambridge University Press.

Lawless, K. A., \& Pellegrino, J. W. (2007). Professional development in integrating technology into teaching and learning: Knowns, unknowns, and ways to pursue better questions and answers. Review of Educational Research. 774), 575-614.

Liu, T. Y., \& Chu, Y. L. (2010). Using ubiquitous games in an English listening and speaking course: Impact on learning outcomes and motivation. Computers \& Education, 52(1), 1-12.

Marino, M., Israel, M., Beecher, C. C., \& Basham, J. D. (2013). Students' and teachers' perceptions of using video games to enhance science instruction. Journal of Science Education Technology, 22(5), 667-680. DOI 10.1007/s10956-012-9421-9

Miles M. B., Huberman A. M. (1994). Qualitative data analysis: An expanded sourcebook (2nd ed.). Thousand Oaks, CA: Sage.

Moersch, C. (1995). Level of technology implementation (LoTi): A framework for measuring classroom technology use. Learning and Leading with Technology, 23(3), 40-42.

Morris, M. W., Leung, K., Ames, D., \& Lickel, B. (1999). Views from inside and outside: Integrating emic and etic insights about culture and justice judgments. Academy of Management Review, 24, 781-796.

National Academy of Sciences. (1996). National science education standards. Washington, DC: National Academy Press. Retrieved from http://www.google.com/url?sa=t\&rct=j\&q=\&esrc=s\&so urce $=$ web\&cd $=4 \& v e d=0 C E A Q F j A D \& u r l=h t t p: / / w w w . c s$ un.edu/science/ref/curriculum/reforms/nses/nsescomplete.pdf\&ei=oxE3UpWEBafF2AXi_oD4Cg\&usg=AF QjCNF3hhWrH110sLjyTlubE8oFkwqi2Q\&bvm=bv.5216 4340,d.b2I

National Academy of Sciences. (2010). Rising above the Gathering Storm, Revisited: Rapidly Approaching Category 5. Washington, DC: National Academies Press.

National Commission on Excellence in Education (NCEE). 1983. A nation at risk: The importance of educational reform. Retrieved from https://www2.ed.gov/pubs/NatAtRisk/risk.html

National Research Council. (2012). A framework for k-12 science education: Practices, crosscutting concepts, and core ideas. Washington, DC: The National Academies Press.

National Science and Technology Council. (2011). The federal science, technology, engineering, and mathematics (STEM) education portfolio. Retrieved from http://www.whitehouse.gov/administration/eop/ ostp/nstc/committees/costem

National Science Board. (2006). America's pressing challenge: Building a stronger foundation. Available from National Science Foundation. (NSB0602). Retrieved from http://www.google.com/url?sa=t\&rct=j\&q=\&esrc=s\&so urce=web\&cd $=1 \&$ ved $=0 C C k Q F j A A \& u r l=h t t p: / / w w w . n s f$ gov/statistics/nsb0602/nsb0602.pdf\&ei=JhA3UpmxPK GA2AX-3YCoBw\&usg=AFQjCNH sqPs1bFIWBUmxNDiSBIVKaxYQ\&bvm=bv.52164340,d.b2

Newman, J. W., Abell, S. K., Hubbard, P. D., McDonald, J., Otaala, J., \& Martini, M. (2004). Dilemmas of teaching 
inquiry in elementary science methods. Journal of Science Teacher Education, 15(4), 257-279.

Novak, E. \& Wisdom, S. (2016, in press). Improving preservice elementary teachers' science engagement through 3D printing technology. Journal of Immersive Education.

Piburn, M., Sawada, D., Turley, J., Falconer, K., Benford, R., Bloom, I., \& Judson, E. (2000). Reformed teaching observation protocol (RTOP): Reference manual (ACEPT Technical Report No. IN00-3). Tempe, AZ: Arizona Collaborative for Excellence in the Preparation of Teachers. Measuring Reform Practices in Science and Mathematics Classrooms: The Reformed Teaching Observation Protocol. Retrieved from http://physicsed.buffalostate.edu/AZTEC/rtop/RTOP_f ull/PDF/RTOP_ref_man_IN003.pdf

Reed, J. and Procter, S. (eds) (1995) Practitioner research in health care:The inside story, London: Chapman and Hall.

Rogoff, B. (1990). Apprenticeship in thinking: Cognitive development in social context. New York: Oxford University Press.

Russell, M., Bebell, D., O'Dwayer, L., \& O'Connor, K. (2003). Examining teacher technology use: Implications for preservice and inservice teacher preparation. Journal of Teacher Education, 54(4), 297-310.

Shenton, A.K. (2004). Strategies for ensuring trustworthiness in qualitative research projects. Education for Information, 22, 63-75.

Slotta, J. \& M. Linn, M. (2009), WISE science: Web-based inquiry in the classroom NY: Teachers College Press.

Srivastava, P., \& Hopwood, N. (2009). A practical iterative framework for qualitative data analysis. International Journal of Qualitative Methods, 8(1), 76-84.

Sun, K., Lin, C., \& Wang, S. (2010). A 3-D virtual reality model of the Sun and the Moon for e-learning at elementary schools. International Journal of Science and Mathematics Education, 8(4), 689-710.

Sung, H. \& Hwang, G. (2013). A collaborative game-based learning approach to improving students' learning performance in science courses. Computers \& Education, 63, 43-51.

Toledo, C. (2005). A five-stage model of computer technology integration into teacher education curriculum. Contemporary Issues in Technology and Teacher Education, 5(2), 177-191.

Triangle Coalition for STEM Education (2017, March 26). Math and science education funding. Retrieved from www.trianglecoalition.org/president-calls-formore-stem-teachers-grads.

U.S. Congress Joint Economic Committee. (2012). STEM education: Preparing for the jobs of the future. Retrieved from http://www.google.com/url?sa=t\&rct=j\&q=\&esrc=s\&so urce=web\&cd=1\&ved=0CCsQFjAA\&url=http://www.jec. senate.gov/public/index.cfm?a=Files.Serve\&File_id=6a aa7e1f-9586-47be-82e7-

326f47658320\&ei=TRE3UpCjNOTF2QWMs4D4CA\&usg =AFQjCNGonTJ74BDEYSZ4kofuZK5faaMnPw\&bvm=bv. 52164340,d.b2I

Veal, W. R., \& MaKinster, J. G. (1999). Pedagogical content knowledge taxonomies. Electronic Journal of Science Education, 3(4): Retrieved from http://wolfweb.unr.edu/homepage/crowther/ejse/veal mak.html

Vygotsky, L. S. (1978). Mind in society: The development of higher psychological processes Cambridge, Mass.: Harvard University Press.

Wallerstein, I. (1998) Utopistics, or Historical Choices of the Twenty First Century. New York, NY: New Press.

Wells G. (2000). Dialogic inquiry in education. In Lee C., Smagorinsky P. (Eds.) Vygotskyian perspectives on literacy research (pp. 51-85). New York: Cambridge University Press.

Wenger, E. (1998) Communities of practice: learning, meaning, and identity. Cambridge University Press.

Wu, H-K., Lee, S. W-Y., Chang, H-Y., Liang, J-C. (2013). Current status, opportunities and challenges of augmented reality. Computers \& Education, 62, 41-49. 


\section{Appendix}

A description of a virtual reality activity embedded in the science methods course

\section{QUEST: We Are SciTeachers!}

1. Establish your dream team - a group of three or four: The goal of this quest is to simply play with Second Life (SL), with your dream team, and see how your group can solve the quests below within a scheduled time period- 90 minutes. In the meantime, I will be your facilitator. If you have any questions during the activity, feel free to IM to my avatar.

Full SL name: evesapple75 Kuhn (a whole class facilitator)

2. Assign a role to each team member: You will need a Facilitator who will lead your team, a Recorder who will record game strategies and tactics, and a Photographer who will take snapshots as your team explores selected islands. Short activity reports in Word Document, will also be required as documentation.

3. Before you meet in the virtual world, brainstorm how your team will finish this quest or how it will explore science-related islands in time-by developing some basic strategies, rules, confirming roles, and tasks for the quest. For instance, you can make rules like the following: Each group member must send one sentence that captures the experience on the SL Orientation Island to your SL recorder. When the team is on an island, each team member will move together with the others. Or, each team member may explore the island individually, and teleport team members-if he or she finds interesting sites within the island.

4. Start your VR activity by offering friendship to your group members and the instructor. Now, you can IM, and teleport each other to different islands and places.

5. Open up the PDF document entitled Science-Related Places in Second Life from our Blackboard, under "Virtual Reality Science Field Trips." See what islands are available, and evaluate where your dream team wants to explore.

$>$ By using the SEARCH button, teleport to at least five science-related islands on the list, as a team, and explore. Make sure that you open up a mini-map at each island and use it (the yellow dot is you; and the green dots are others).

$>$ Recommend Islands from the list: Euclidia Space Planetarium, The Abyss Observatory, Synthetic Biology Interactive, Elucian Islands, MICA, Energy Island, the Neil A. Armstrong Library \& Archives, Genome Island, Fire Sabre's Volcano, the Jet Propulsion Laboratory, Virtual Hallucinations, Science Friday, The Bell of the Firmament, Cloud Chateau, David Rumsey Maps, Astronomy 2009 Island, Apollo Moon Landing, Virtual Stomach Museum, Tech Museum of Innovation, and the Spaceflight Museum.

6. Upload your Word Document to the VR table on our wiki page. Make sure that you click the SAVE button at the bottom of the wiki page when you are finished-one document per one group. Also, send this same document to your team members so you have multiple backup files.

7. Individually, answer the following questions in Word Document and upload it to our class PBwiki.

a. What skills did you learn in terms of science content, vocabulary, or inquiry skills?

b. How did you grow in your confidence with, and abilities in, digital skills and virtual reality?

c. What do you want to report about your experiences with virtual reality, particularly regarding its potential(s) for science education?

d. How do you think you might incorporate virtual reality—and other similar virtual worlds—-for science education activities in the future in your classrooms?

\section{Congratulations!}


This page is intentionally left blank www.iejee.com 